decarboxylase by McCann. The possible importance of polyamines and ornithine decarboxylase in skin tumour promotion and as markers for compounds with antipromoting actions are well described by O'Brien and by Verma and Boutwell who were pioneers in the field. There is also a first-rate and - at the time of writing comprehensive evaluation of methods for polyamine measurement by Seiler who is responsible for much of the methodology now in routine use. Isolation and analysis of novel polyamines found in thermophiles are covered in a chapter by Zappia and colleagues. The remainder of the book contains a heterogeneous collection of contributions on carcinogenesis, polyamine degradation, their putative roles in macrophage function, relationship to chalones, suppression of lymphocyte function, excretion and conjugation, and value as tumour markers. These articles are often highly speculative and, while thought provoking, are much less rigorous.

Several important contributors to polyamine research are missing from this volume (for example it is unfortunate that there is no chapter from $\mathrm{H}$. and C.W. Tabor on their polyamine-deficient mutants), and the two-year delay between writing and publication has meant there are a number of significant omissions in content. However, as a source book for scholars of a wide range of interests, it should prove valuable.

Anthony E. Pegg is Professor in the Department of Physiology at The Milton S. Hershey Medical Center, Hershey, Pennsylvania. Hannu Pösö is Docent in the Department of Biochemistry at the University of Helsinki.

\section{Air of learning}

\section{Peter S. Liss}

Air in Danger: Ecological Perspectives of the Atmosphere. By G. Breuer. Pp.189. (Cambridge University Press: 1980.) Hbk $£ 10, \$ 24.95$; pbk £3.50, \$7.95.

IMAGINE you are a scientist or scientific journalist invited to attend a research meeting on a topic which is not your speciality. You enjoy the meeting and become sufficiently interested in the topic to follow it up by reading, and visiting and writing to experts in the field. Then you decide to write up not only what you have learnt but also the various stages in the learning process, and persuade major publishers to issue the result in both German and English.

Although no biographical details of the author of Air in Danger are given (and, for once, I felt their absence to be a real loss), this would appear to be the way in which this book came into being. Georg Breuer attended, as an observer, the Dahlem Conference, "Global Chemical Cycles and Their Alterations by Man', held in Berlin in November, 1976. This spurred him to find out more about a major topic of the meeting, the way in which the major atmospheric gases - nitrogen, oxygen and carbon dioxide - are cycled in the environment. The chapters of the book chronicle the author's education as to how normal biological processes transfer these elements between the various environmental reservoirs and also how humans are influencing this cycling. Quite properly, considerable attention is given to the photosynthesis/respiration-decomposition reactions since these truly dominate the environmental chemistry of the gases considered, as well as that of many other substances.

Inevitably, this way of setting about writing a book has its disadvantages. Someone who is self-taught spends considerable time exploring what turn out to be blind alleys (for example, several pages in the first chapter deal with what is well known to be the "non-problem" of whether fossil fuel combustion can significantly deplete atmospheric oxygen) and also tends to over-detailed explanations.

On the plus side the approach adopted has the freshness inherent in knowledge newly acquired. What is not clear is what type of reader will want to share in the author's learning experience, since each of us learn in an individualistic and idiosyncratic manner. The book is certainly timely in that it presents in considerable detail much of the background behind the current debate over Lovelock's Gaia hypothesis, recently expounded in his book Gaia: A New Look at Life on Earth (Oxford University Press, 1979 - see Nature 282, 154 for review).

The translation (by Peter Fabian) from the German original reads very well, but the English edition should never have been titled as it is. The main title gives the impression of a gloom and doom, pollution-orientated book which it certainly isn't. In fact, the author is to be commended for treading a very sensible line between natural and anthropogenic effects and the book's main title does his care a considerable injustice.

Peter S. Liss is Reader in the School of Environmental Sciences, University of East Anglia, and Scientific Advisor in the Environmental Studies Section at CEGB Headquarters.

\title{
Stimulating energy transfer
}

\section{A.J. McCaffery}

\section{Introduction to Molecular Energy Transfer. By James T. Yardley. Pp.308. (Academic: 1980.) \$34, £19.20.}

THE microscopic processes of energy transfer - the molecular-level events in the gas, liquid and solid phases of matter have been the subject of intense research interest for a number of years, and a book which attempts to draw together the wideranging strands of this field is most welcome. The topics covered in this volume reflect both the author's own research interests and the major thrusts of recent research, and thus the bulk of the book deals with vibrational energy transfer. Some of the modern experimental methods are reviewed in detail, as, more briefly, are the classical methods of ultrasonic dispersion and shock tube techniques. Gas phase vibration-to-translation and vibration-to-vibration transfer both receive detailed treatment and there is a short chapter on vibrational relaxation in liquids and inert materials. Included as a basis for the treatment of vibrational processes is a comprehensive theoretical development of the internal vibrational modes of molecules.

The remainder of the book is taken up with discussion of a diverse and interesting collection of topics. These range from radiationless electronic transfer in molecules, to the less known phenomena of collision-induced fine structure transitions in atoms and quenching of atomic excitation by curve crossing.

One interesting feature is a derivation of the Born approximation as early on as p. 8 , and its subsequent usage runs like a thread through the wide range of fields covered in the later chapters, providing a useful physical insight in to the individual transfer processes.

The difficulties of producing a completely up-to-date text are apparent, though references to work as late as 1978 are relatively frequent in some sections. Perhaps a more substantial criticism is that the book's purpose is not entirely clear. It is a mixture of pedagogy, in that it covers such basics as group theory, the hydrogen atom, LCAO-MO model and determinantal basis functions, and review. The coverage of rotational energy transfer is slightly disappointing by comparison to the treatment of its vibrational counterpart, as is the absence of discussion of scattering theoretic, semi-classical and classical trajectory studies of energy transfer.

Despite these small criticisms, Yardley's book is a stimulating and readable account of an important research topic with a number of interesting and novel features in its development. It should prove popular as a basic graduate text for North American universities and as a valuable source of methods and theory to research workers.

A.J. McCaffery is Reader in Molecular Sciences at Sussex University whose research interests are in the study of gas phase molecular dynamics using laser techniques. 